\title{
Prospective study of patterns of surgical management in adults with primary cutaneous melanoma at high risk of spread, in Queensland, Australia
}

Dol:

$10.1002 /$ jso.24013

\section{Document Version \\ Accepted author manuscript}

Link to publication record in Manchester Research Explorer

Citation for published version (APA):

Smithers, B. M., Hughes, M. C. B., Beesley, V. L., Barbour, A. P., Malt, M. K., Weedon, D., Zonta, M. J., Wood, D., Triscott, J. A., Bayley, G. J., Brown, L. J., Allan, C. P., D'Arcy, J., Williamson, R., Khosrotehrani, K., \& Green, A. (2015). Prospective study of patterns of surgical management in adults with primary cutaneous melanoma at high risk of spread, in Queensland, Australia. Journal of Surgical Oncology, 112(4), 359-365.

https://doi.org/10.1002/jso.24013

Published in:

Journal of Surgical Oncology

\section{Citing this paper}

Please note that where the full-text provided on Manchester Research Explorer is the Author Accepted Manuscript or Proof version this may differ from the final Published version. If citing, it is advised that you check and use the publisher's definitive version.

\section{General rights}

Copyright and moral rights for the publications made accessible in the Research Explorer are retained by the authors and/or other copyright owners and it is a condition of accessing publications that users recognise and abide by the legal requirements associated with these rights.

\section{Takedown policy}

If you believe that this document breaches copyright please refer to the University of Manchester's Takedown Procedures [http://man.ac.uk/04Y6Bo] or contact uml.scholarlycommunications@manchester.ac.uk providing relevant details, so we can investigate your claim.

\section{OPEN ACCESS}




\section{Prospective study of patterns of surgical management in adults with primary}

cutaneous melanoma at high risk of spread, in Queensland, Australia

B Mark Smithers FRACS ${ }^{1}$, Maria Celia B Hughes MMedSc ${ }^{2}$, Vanessa L Beesley $\mathrm{PhD}^{9}$, Andrew P Barbour FRACS ${ }^{1}$, Maryrose K Malt B Bus ${ }^{2}$, David Weedon MD, FRCPA $^{3}$, Mark J Zonta FRACS ${ }^{4,13}$, Dominic J Wood FRCPA ${ }^{5}$, Joseph A Triscott FRCPA $^{5}$, Gerard J Bayley FRACS ${ }^{1,6}$, Lee J Brown FRACS ${ }^{7}$, Christopher P Allan FRACS $^{1,8}$, Justin D'Arcy FRACS ${ }^{14}$, Richard Williamson FRCPA ${ }^{10}$, Kiarash Khosrotehrani MD, PhD, FACD ${ }^{11}$, Adèle C Green PhD FAFPHM ${ }^{2,12}$

${ }^{1}$ Queensland Melanoma Project, Discipline of Surgery, The University of Queensland, Princess Alexandra Hospital, Woolloongabba, Qld 4102, Australia

${ }^{2}$ Cancer and Population Studies Group, QIMR Berghofer Medical Research Institute, Brisbane, Qld 4029, Australia

${ }^{3}$ Sullivan Nicolaides Pathology, Indooroopilly, Qld 4068, Australia

${ }^{4}$ The Townsville Hospital, Townsville, Qld 4810, Australia

${ }^{5}$ IQ Pathology, South Brisbane, Qld 4101, Australia

${ }^{6}$ Phoenix Plastic Surgery Institute, Greenslopes, Qld 4120, Australia

${ }^{7}$ Kawana Private Hospital, Sunshine Coast, Qld 4575, Australia

${ }^{8}$ Mater Health Services, South Brisbane, Qld 4101, Australia

${ }^{9}$ Gynaecological Cancers Group, QIMR Berghofer Medical Research Institute, Brisbane, Qld 4029, Australia General Hospital, Hospital Road, Nambour, Qld 4560, Australia

${ }^{10}$ Zenith Specialist Pathology, South Brisbane, Qld 4101, Australia

${ }^{11}$ Experimental Dermatology Group, The University of Queensland Centre for Clinical Research \& The University of Queensland Diamantina Institute, Brisbane, Qld 4029, Australia

${ }^{12}$ CRUK Manchester Institute and Institute of Inflammation and Repair, University of Manchester, England 
${ }^{13}$ Mater Medical Centre, Pimlico, Qld Australia

${ }^{14}$ Nambour General Hospital, Hospital Road, Nambour, Qld 4560, Australia

Corresponding Author: Prof Adèle C.Green

QIMR Berghofer Medical Research Institute Locked Bag 2000, Royal Brisbane Hospital Qld 4029

Australia

Ph: 61733620234 Fax: 61738453503

Email: adele.green@gimrberghofer.edu.au

Running Head: Patterns of management for high-risk primary melanoma

Funding: NHMRC Australia (Grant no. 552429)

Disclosure: The authors have no financial disclosures

Running Head: Management of high-risk primary melanoma

\section{Synopsis for Table of Contents}

Variations in diagnostic biopsy procedure and performance of sentinel node biopsy were assessed in 787 Australian patients with cutaneous melanoma clinical stage 1b or 2. Diagnostic procedure influenced initial tumor microstaging. Treating doctor, patient and tumor characteristics all influenced whether sentinel node biopsy was performed. 


\section{ABSTRACT}

Background: Knowledge of variation in diagnosis and surgery in high-risk primary melanoma patients is limited. We assessed frequency and determinants of diagnostic procedures, wide local excision (WLE) and sentinel lymph node biopsy (SLNB).

Methods: People in Queensland newly diagnosed with melanoma, clinical stage 1b or 2, were recruited prospectively. Patient information was collected from questionnaires and pathology records. Differences in surgical procedures in relation to host and tumor characteristics were assessed.

Results: In 787 participants, primary melanoma was diagnosed by surgical excision (74\%), shave (14\%), punch (12\%) or incisional (1\%) biopsy. General practitioners (GPs) diagnosed $80 \%$. Diagnostic procedure differed by remoteness of residence, health sector, treating doctor's specialty and melanoma site and thickness. 766 patients had WLE, $86 \%$ by surgeons. Of 134 residual melanomas, $13(10 \%)$ were $\leq 1 \mathrm{~mm}$ at diagnosis but $>1 \mathrm{~mm}$ at WLE, mostly after shave biopsy. SLNB was performed in 261 (33\%) patients. SLNB was more common in those under 50, in remoter locations or treated by GP initially, and less common with head and neck melanoma.

Conclusion: Diagnostic and surgical procedures for primary melanoma vary substantially and partial biopsy can influence initial tumor microstaging. Patient, tumor and doctor characteristics influence SLNB practice.

Key Words: excision, melanoma, sentinel node 


\section{Introduction}

Cutaneous melanoma continues to be a serious public health problem for white populations around the world, but the clinical picture has changed over the last 50 years. Formerly a rare cancer with high mortality, melanoma is now a cancer of relatively high incidence and low mortality as clinical and public awareness of the disease have risen [1]. The majority of melanomas are now thin $(<1 \mathrm{~mm}$ in thickness) when diagnosed and have not spread beyond the skin. In the Queensland population with the highest known incidence rates globally, 20-year survival for people presenting with thin melanoma is $96 \%$ [2]. Despite this favourable outlook for the majority, deaths from thin melanoma in high-incidence populations like Queensland are not uncommon, such that currently more people die from thin melanomas than from thick melanomas (>4 mm) in Queensland [3] . Primary melanomas thicker than $1 \mathrm{~mm}$ have estimated 10 -year survival rates ranging from $80 \%$ to $40 \%$ [4]. This is despite complete surgical excision of the primary with or without SLNB, though patterns of management from presentation to definitive surgical treatment can vary. Controversies exist about the method of diagnosis [5], timing of WLE [6] and whether SLNB should be routinely performed [7-9]. There is also a dearth of knowledge about how initial management decisions might affect not only ultimate survival, but also quality of life, particularly among patients who are at high risk of spread [10].

Several previous studies have focused on initial biopsy techniques [11-13] and the time from diagnostic biopsy to WLE $[6,14]$. For primary melanoma $>1 \mathrm{~mm}$ in thickness at time of diagnosis, studies of rates of SLNB $[15,16]$ have often been limited by their reliance on clinical databases that lacked important clinicopathological factors or were hampered by missing information for sizable 
numbers of patients. Given the high number of deaths due to primary melanoma in Australia, with over 9,300 deaths from thin melanomas in the state of Queensland alone in the most recent 5 years [3], we aimed to assess patterns of surgical management in the subgroup of primary melanoma patients who have a high risk of spread, namely those with stage $1 \mathrm{~b}$ and 2 disease [4]. We also investigated potential change in staging of primary melanoma from diagnosis to definitive surgery according to diagnostic surgical technique used in this high-risk subgroup.

\section{Patients and Methods}

Case ascertainment

People diagnosed with a clinical stage 1b or 2 cutaneous melanoma [4] between October 2010 and October 2014 were recruited prospectively through a variety of clinics, namely the Multidisciplinary Melanoma Clinic at the Princess Alexandra Hospital and the Specialist Outpatient Department of the Royal Brisbane and Women's Hospital in Brisbane; through two regional hospitals, the Nambour General Hospital and the Specialist Outpatient Department of Townsville General Hospital in north Queensland, and through the private practices of surgeons associated with these hospitals who have an interest in managing cutaneous melanoma [10]. In addition people with stage $1 \mathrm{~b}$ or 2 cutaneous melanomas initially managed by other private specialists and primary care practitioners were identified through 3 private pathology companies in Queensland.

Eligible patients ascertained through clinics or private practices were invited to participate by their treating doctors (or by study personnel with doctor's permission) and were provided with a patient information and consent form. For ascertainment 
of patients in the community through pathology laboratories, pathologists identified eligible patients with newly-diagnosed melanoma and included a standard note on the computer-generated histopathology report. This note informed the treating doctors about the study and asked the doctors to inform the pathology company if their patients should not be contacted. When no objection was received within 2 weeks, the pathology company sent a standard introductory letter and study brochure to the potentially eligible patients with a request for permission to release their details to study personnel. Only the contact details of patients who actively granted permission were disclosed by the pathology company and these patients were then invited to participate in the study and provided with patient information and consent forms. Patients were excluded if they were aged less than 16 years (Queensland Health deems 16 years to be the age of consent), if they were physically or mentally unable to complete a written questionnaire, if subsequent definitive surgical diagnosis proved the primary melanoma was ineligible eg pathology showed presence of satellitosis. (Use of imaging techniques for staging following the primary diagnosis was only performed if needed at the discretion of the treating surgeon.) All study participants provided written informed consent and the study was approved by the Ethics Committees of the Metro South Hospital and Health Service of the Princess Alexandra Hospital and the Queensland Institute of Medical Research.

\section{Baseline data collection}

Participants provided personal details including previous melanoma and family history using standard self-completed questionnaires. Patients' place of residence was categorised as major city, inner regional area, outer regional area or a remote 
location using the Australian Statistical Geographical Standard Remoteness Structure $(2001)[17,18]$. Details of index primary melanomas were extracted from histopathology reports including anatomical site, histological classification, thickness $(\mathrm{mm})$, presence of mitoses (per $\mathrm{mm}^{2}$ or per hpf) and ulceration. In addition, information about the initial treating doctor (GP, GP in a skin cancer clinic, specialist), diagnostic biopsy procedure (excision, incision, shave, punch) and the surgical treatment performed (WLE including if residual tumor present or absent, with or without SLNB) was obtained from pathology records. Margin of excision was not recorded. For SLNB, specialty of treating doctor, interval (days) between diagnostic biopsy and definitive surgery, biopsy site, total number of sentinel lymph nodes removed, number of involved (positive) nodes and size of largest node (in $\mathrm{mm}$ ) were recorded prospectively from pathology reports. Primary tumor and clinical staging of melanomas were determined [4].

Statistical analysis

Differences in diagnostic procedure and operative details of definitive surgery in relation to personal characteristics and site of melanoma were assessed using chisquared tests for categorical or nominal variables, ANOVA for age and Wilcoxon rank sum test for time between diagnosis and surgery. Prevalence ratios (PR) and 95\% confidence intervals $(\mathrm{Cl})$ were estimated using log binomial regression models to determine the associations between decision to undergo SLNB (yes/no) and personal characteristics, diagnostic procedure and histological characteristics of primary melanoma, and similarly for associations with occurrence of positive nodes (none/1 or more). These analyses were adjusted for other related factors, namely age, sex, melanoma thickness and ulceration for SLNB; and age and sex only (due to small number of people with positive nodes) for SLNB positivity. All analyses were 
performed with Statistical Analysis Software, version 9.2 (SAS Institute, Cary, USA).

\section{Results}

We contacted 1254 patients newly diagnosed with primary invasive cutaneous melanoma, of whom 825 (66\%) agreed to participate. Of these 825,38 were found to be ineligible after consent leaving 787 participants. The mean age of participants at diagnosis was 62 years and $57 \%$ were male. The trunk was the most common site of melanoma (35\%) while head and neck, upper limbs and lower limbs were each affected in similar proportions (around $22 \%$ )(Table I). Of the $787,23 \%$ reported a previous melanoma and $30 \%$ a first-degree relative with melanoma. Comparison of our study cohort showed no significant differences in age or sex distributions when compared with total number of cases aged less than 80 years diagnosed in Queensland within the study period as recorded by the Cancer Registry.

GPs diagnosed $80 \%$ of the stage $1 \mathrm{~b}$ or 2 melanomas, $24 \%$ of whom worked in dedicated skin cancer clinics. Overall the most common diagnostic method was surgical excision (74\%), followed by shave (14\%), punch $(12 \%)$ or incisional $(1 \%)$ biopsy. WLE was the diagnostic procedure in 16 patients. No further surgery was performed after diagnostic surgical excision in 9 patients either because clear margins had been achieved $(n=4)$ or for reasons unstated $(n=5)$.

Diagnostic procedure differed significantly by patient's place of residence, health care sector, specialty of treating doctor, site and thickness of the primary melanoma (Table II). Of 674 patients living in major cities and inner regional areas, 15\% were diagnosed by shave biopsies compared with $7 \%$ of those in outer regional/remote 
areas $(p=0.007)$. Of patients treated in public hospitals, $79 \%$ and $9 \%$ had melanoma diagnosed by excision and shave biopsies respectively compared with $70 \%$ and $18 \%$ respectively among private patients $(p=0.002)$. Of the 633 diagnostic procedures performed by GPs, $75 \%$ were excision biopsies, $13 \%$ were punch biopsies and $12 \%$ were shave biopsies compared with 79 diagnostic procedures by dermatologists, $53 \%$ of which were excision, $8 \%$ punch and $39 \%$ shave biopsies. Surgeons mostly performed excision biopsies (85\% of 68 diagnostic procedures) (Table II).

Melanomas on all sites were most commonly diagnosed by excision biopsy. Punch or incision biopsy was least used for melanomas on the trunk (Table II). The mean thickness of melanomas diagnosed by shave biopsy $(1.1 \mathrm{~mm})$ was significantly less $(p<0.0001)$ and time to definitive surgery significantly less on average (17 days) $(p<0.0001)$ compared with melanomas diagnosed by other procedures (Table II). A total of 766 patients had follow-up WLEs, $86 \%$ of which were performed by surgeons (Table I). Residual tumor was present in 203 (27\%) of these 766, and the proportion varied significantly by diagnostic procedure with $83 \%$ of 96 punch biopsies and $48 \%$ of 111 shave biopsies having residual tumor, compared with $13 \%$ of 559 excision biopsies $(p<0.0001)$. Tumor thickness after diagnostic surgery was available for 134 melanomas with residual tumor, of which $13(10 \%)$ were reported $\leq 1 \mathrm{~mm}$ thick at diagnosis, but $>1 \mathrm{~mm}$ at WLE. This change of measured thickness was significantly associated $(p=0.001)$ with diagnostic procedure and occurred in 4 of 40 shave biopsies, 1 of 24 excisions and 2 of 70 punch/incision biopsies. In addition, 32 of the 766 patients underwent at least 2 WLEs (Table I), and this was also associated with diagnostic procedure, involving $9 \%$ of all shave $(n=111)$ biopsies 
compared with $3 \%$ of all (559) excision biopsies and $4 \%$ of all (96) punch biopsies $(p=0.021)$.

Of the 766 patients who had follow-up WLEs, 261 (34\%) also had a SLNB (Table I). After adjustment for age, sex, melanoma thickness and ulceration, the decision to undergo SLNB was significantly less common among those aged 50 or more compared with younger patients, and especially less frequent among those aged 70 years old or more (PRadj:0.31; 95\% Cl:0.23, 0.44) (Table III). A significantly higher proportion of outer regional/remote residents underwent SLNB (PRadj:1.41; $95 \% \mathrm{Cl}: 1.14,1.74)$ compared with residents of major cities (further adjustment by type of treating doctor did not alter this result), more of those who lived with a partner (PRadj: 1.25; 95\%Cl: 0.99, 1.58), as well as more of those with a first degree relative with melanoma than those without (PRadj:1.28; 95\%Cl:1.07, 1.53). SLNB was performed twice as frequently among patients with melanomas thicker than $1 \mathrm{~mm}$ compared with stage $1 \mathrm{~b}$ melanomas and in those with primary melanomas on sites other than the head and neck. People who had a past history of melanoma less commonly underwent SLNB compared to those without previous melanoma (PRadj: $0.65 ; 95 \% \mathrm{Cl}: 0.48,0.90)$ and significantly less patients initially treated by surgeons and other specialists elected to undergo SLNB compared with patients of GPS (PRadj: 0.75; 95\%Cl:0.59, 0.97) (Table III). Finally SLNB was significantly less prevalent among patients with melanomas lacking a common or clearly defined histological type (Table III).

The sentinel node was positive in 38 (15\%) patients and a positive result was associated with increasing melanoma thickness, ulceration of the primary melanoma and increasing T-stage after adjustment for age and sex (see Supplemental Table). 
There was no association between node positivity and sex, age at diagnosis, relationship status, remoteness of residence, previous melanoma history or immediate family history, health service sector, speciality of initial treating doctor, diagnostic procedure, site of melanoma or histologic classification of the primary, although numbers were small.

\section{Discussion}

We have shown that in Queensland patterns of surgical management vary widely for people diagnosed with primary melanoma stage $1 \mathrm{~b}$ or 2 at high risk of spread. Primary care practitioners, a quarter of whom worked in dedicated skin cancer clinics, diagnosed $80 \%$ of the primary melanomas in this cohort, mostly by excision biopsy (74\%). Surgeons diagnosed $9 \%$ of the melanomas, mostly by excision biopsy (85\%). Dermatologists, who diagnosed 10\%, performed excision biopsy for half the diagnoses and shave biopsy for around 40\% (versus $12 \%$ among GPs). More people living in major cities and inner regional areas and those treated in the private sector were diagnosed by shave biopsies than those living in outer regional/remote areas and those treated in the public sector respectively. On the relatively few occasions that punch biopsies were performed, the melanomas tended to be thicker $(1.9 \mathrm{~mm}$ on average) and to be located on the head and neck or lower limb, perhaps partly reflecting that large lentigo maligna melanomas on cosmetically sensitive sites are difficult to remove entirely; or that thick melanomas may require partial biopsy for diagnosis. Melanomas diagnosed by shave biopsy were significantly thinner on average $(1.1 \mathrm{~mm})$ than other melanomas perhaps reflecting a tendency for primary treating physicians to reserve shave biopsies for thin, flat lesions. 
The overall low rate of $26 \%$ of diagnoses performed by non-excisional biopsy in our large unselected Queensland series was similar to the rate of $23 \%$ seen in another large Australian series in 2000 , although the latter was not restricted to high-risk primary melanomas and included in situ melanomas[11]. Much higher nonexcisional biopsy rates have been reported in North America. For example in a series of 709 primary melanoma patients who were clinically node-negative and had been referred to a surgical oncology department in Oregon between 1998 and 2012 for SLNB, non-excisional biopsies had been performed in over 50\% (punch, 23\%; shave, 34\%) [12], and among a survey of some 100 Canadian family physicians, only $20 \%$ reported they would always perform an excisional biopsy of skin lesions suspicious for melanoma [19]. The main potential problem with partial biopsies relates to diagnostic accuracy and accuracy of microstaging of thicker lesions. In our series of 134 melanomas with complete thickness data available, $25 \%$ of melanomas diagnosed by shave biopsy were upstaged from $\leq 1 \mathrm{~mm}$ to $>1 \mathrm{~mm}$ thickness compared with $3 \%$ diagnosed by punch biopsy and $4 \%$ by excisional biopsy, which could have influenced the potential to discuss the role of sentinel node biopsy in these patients. These findings are slightly at variance with the Oregon series, where the $\mathrm{T}$ stage changed after a punch biopsy in $23 \%$, after a shave biopsy in $8 \%$ and after excision in $2 \%$, and in particular in $13 \%$ of melanoma diagnosed by punch or shave biopsies, measured thickness changed from $<1 \mathrm{~mm}$ to $>1 \mathrm{~mm}$ [12]. Countering these data, a study assessing shave biopsy in 490 patients in a Texas Veterans' hospital found the T stage to be appropriately assessed in $99 \%$ of patients [13] when only $14 \%$ of patients had an excision biopsy, mostly for thicker lesions (mean $2.28 \mathrm{~mm}$ ) compared with a mean thickness of $<1 \mathrm{~mm}$ for punch and shave biopsied lesions. In an Australian study of melanoma (all stages) at a tertiary referral centre, 
histopathologic misdiagnosis was more common for melanomas diagnosed with punch and shave biopsies than with excisional biopsy, and punch and shave biopsies also led to microstaging inaccuracy [20]. Tumor thickness was the most important factor associated with microstaging inaccuracy after partial biopsy: inaccuracy increased nearly 2 -fold for every $1 \mathrm{~mm}$ increase in tumor thickness[20]. To date most of the literature assessing non-excisional biopsies has not assessed the method or completeness of biopsy, or the training or experience of the person doing the partial biopsy. This may be relevant when it has been shown that a deep shave biopsy is superior to a punch or superficial shave biopsy for diagnostic accuracy[21]. Tumor seeding may also be a rare outcome of punch biopsy [22]. Despite these drawbacks, studies have reported that method of biopsy does not affect melanoma-specific survival $[12,13,23]$.

In high-risk primary melanoma patients it is reasonable to consider a SLNB for improved staging and extra prognostic information $[8,24]$. SLNB was performed in a third of the 787 study patients, which is less than in other population studies $[15,16,25]$ that were mostly performed prior to the publication of the MSLT 1 trial [8]. Our study began after that publication. Although most of study patients were initially managed by primary care practitioners as are most melanoma patients in Australia, $86 \%$ of patients were treated by surgeons for their WLE and potential SLNB. Notably many of these Queensland patients were at high risk of melanoma a priori because of a self-reported first-degree relative with melanoma (30\%) (though this estimate is likely to be inflated by a degree of false-positive reporting [26]) or a previous melanoma (23\%) yet paradoxically these risk factors significantly affected the decision to undergo SLNB in opposite ways; in the former $28 \%$ more, and the latter $33 \%$ less patients underwent SLNB than those without the respective histories. 
Patients aged under 50, those living with a partner, and those initially treated by a GP opted for SLNB more than others in this high-risk cohort. In addition patients living in outer regional/remote locations were more likely to undergo SLNB than those living in or close to major cities. These patients from more remote locations are typically diagnosed by a GP and then referred to a major centre / specialist managing melanoma, often a substantial distance away. This referral pattern, together with the required travel, may have resulted in the observed tendency for a higher number to undergo SLNB. Factors associated with decreased prevalence of SLNB on the other hand, were having a melanoma on the head or neck, or a melanoma lacking a common or clearly defined histological type. The sentinel node was positive in $15 \%$ and a positive result was associated with increasing melanoma thickness, ulceration of the primary melanoma and increasing $T$ stage. There was no association between sentinel node positivity and patient's sex, age at diagnosis, relationship status, remoteness of residence, previous melanoma history or immediate family history, health service sector, speciality of initial treating doctor, diagnostic procedure, site of melanoma or histologic classification of the primary.

In the US, the records of 18,499 patients in the SEER database who were diagnosed with Stage $1 b$ and 2 melanoma from 1998 to 2001 showed a 43\% SLNB biopsy rate with $12 \%$ of patients having an elective regional node dissection [25]. At the time the authors felt the procedure had been "under used" with lower rates in the elderly, minority populations and primary lesions on the head and neck and trunk. (A later survey of the SEER database in the period 2004 to 2006 , showed that $53 \%$ of eligible patients had a SLNB [27].) In a separate population-based study of 1242 patients with invasive melanoma in North Carolina between 1999 and 2001, 48\% of 
patients had a SLNB. As in most other studies including the present Queensland study, the procedure was more common in patients under 50 years and for melanoma on sites other than the head and neck. Indeed in relation to anatomical site, the decision to proceed to SLNB may be influenced by the potential for morbidity such as risk of injury to the facial nerve for head and neck lesions, and groin wound complications in lower limb sites. In contrast to the Queensland primary melanoma patients, those with thicker melanomas (T3/4) in North Carolina were more likely to have SLNB compared with T2 [15]. A lower rate of SLNB of 34\% was reported in a population-based study of people with primary melanoma $>1 \mathrm{~mm}$ in North East of France in 2004 [16]. Variation in rates of SLNB was related to geographical region, distance from a major referral centre and local health care patterns. Additionally, we have previously shown that patients who elected to undergo SLNB reported significantly worse melanoma-specific symptoms compared with those who did not undergo the procedure [10]. Taken together, it appears that patients' perception of the seriousness of the disease (as influenced by age, personal and family history for example) and non-medical parameters play key roles in the decision to undergo a SLNB.

With the recent publication of the long-term (10 year) outcomes from the MSLT I trial [24], positive prognostic implications for the subgroup of patients with melanoma between $1.2-3.5 \mathrm{~mm}$ were confirmed with survival benefit from SLNB followed by completion lymph node dissection in the subset of patients who had a positive biopsy. Although debated, it has been suggested that there may be a survival benefit for 3-4 patients for every 100 patients within this thickness range that have the procedure [7]. It is clear there is no survival benefit for patients with a melanoma 
greater than $3.5 \mathrm{~mm}$ thick, although there is still prognostic information and early diagnosis for regional disease in patients with a positive biopsy [7]. Whether the long-term outcomes from the MSLT I trial influence SLNB trends will be worthy of assessment in the future. The recent tendency to require sentinel node status as an inclusion criterion in phase III trials of therapies for patients with stage 3 melanoma suggests that the indication for SLNB is likely to expand. This will influence the number of patients with high risk primary melanoma who undergo SLNB.

In conclusion, diagnosis and management of primary cutaneous melanoma requires rational guidelines based on evidence. Our study provides detailed information about the variation in current practices in patients with melanoma at high risk of spread, suggesting the need for further evaluation of patient outcome according to diagnostic and staging methods. Patients should receive appropriate counselling about the role of sentinel lymph node biopsy and general counselling regarding prognosis and future management. 


\section{References}

1. Erdmann F, Lortet-Tieulent J, Schüz J, et al.: International trends in the incidence of malignant melanoma 1953-2008-are recent generations at higher or lower risk? International Journal of Cancer 2013;132:385-400.

2. Green AC, Baade P, Coory M, et al.: Population-Based 20-Year Survival Among People Diagnosed With Thin Melanomas in Queensland, Australia. Journal of Clinical Oncology 2012;30:1462-1467.

3. Whiteman DC, Baade PD, Olsen CM: More People Die from Thin Melanomas (1 mm) than from Thick Melanomas ( $>4 \mathrm{~mm}$ ) in Queensland, Australia. The Journal of investigative dermatology 2014.

4. Balch CM, Gershenwald JE, Soong S-j, et al.: Final Version of 2009 AJCC Melanoma Staging and Classification. Journal of Clinical Oncology 2009;27:6199-6206.

5. Bong JL, Herd RM, Hunter JAA: Incisional biopsy and melanoma prognosis. Journal of the American Academy of Dermatology 2002;46:690-694.

6. McKenna DB, Lee RJ, Prescott RJ, Doherty VR: The time from diagnostic excision biopsy to wide local excision for primary cutaneous malignant melanoma may not affect patient survival. British Journal of Dermatology 2002;147:48-54.

7. Coit $\mathrm{D}$ : Sentinel lymph node biopsy for melanoma: a plea to let the data speak. Annals of surgical oncology 2014;21:3359-3361.

8. Morton DL, Thompson JF, Cochran AJ, et al.: Sentinel-Node Biopsy or Nodal Observation in Melanoma. New England Journal of Medicine 2006;355:1307-1317.

9. Torjesen I: Sentinel node biopsy for melanoma: unnecessary treatment? BMJ (Clinical research ed) 2013;346:e8645.

10. Beesley VL, Smithers BM, Khosrotehrani K, et al.: Supportive care needs, anxiety, depression and quality of life amongst newly diagnosed patients with localised invasive cutaneous melanoma in Queensland, Australia. Psycho-oncology 2014.

11. Kelly JW, Henderson MA, Thursfield VJ, et al.: The management of primary cutaneous melanoma in Victoria in 1996 and 2000. The Medical journal of Australia 2007;187:511-514.

12. Mills JK, White I, Diggs B, et al.: Effect of biopsy type on outcomes in the treatment of primary cutaneous melanoma. American journal of surgery 2013;205:585-590; discussion 590.

13. Mir M, Chan CS, Khan F, et al.: The rate of melanoma transection with various biopsy techniques and the influence of tumor transection on patient survival. J Am Acad Dermatol 2013;68:452-458.

14. Carpenter S, Pockaj B, Dueck A, et al.: Factors influencing time between biopsy and definitive surgery for malignant melanoma: do they impact clinical outcome? The American Journal of Surgery 2008;196:834-843.

15. Stitzenberg KB, Thomas NE, Beskow LM, Ollila DW: Population-based analysis of lymphatic mapping and sentinel lymphadenectomy utilization for intermediate thickness melanoma. Journal of surgical oncology 2006;93:100-107; discussion 107-108.

16. Grange F, Vitry F, Granel-Brocard F, et al.: Variations in management of stage i to stage iii cutaneous melanoma: A population-based study of clinical practices in france. Archives of dermatology 2008;144:629-636.

17. Australian Bureau of Statistics: "Statistical Geography Volume 1: Australian Standard Geographical Classification (ASGC). Catalogue number 1216.0." Canberra, 2001.

18. Australian Institute of Health and Welfare: "Rural, regional and remote health: a guide to remoteness classifications. Catalogue number PHE 53." Canberra, 2004. 
19. Lutz K, Hayward V, Joseph M, et al.: Current biopsy practices for suspected melanoma: A survey of family physicians in Southwestern Ontario. The Canadian journal of plastic surgery = Journal canadien de chirurgie plastique 2014;22:175-178.

20. Ng JC, Swain S, Dowling JP, et al.: The impact of partial biopsy on histopathologic diagnosis of cutaneous melanoma: experience of an Australian tertiary referral service. Archives of dermatology 2010;146:234-239.

21. Pariser RJ, Divers A, Nassar A: The relationship between biopsy technique and uncertainty in the histopathologic diagnosis of melanoma. Dermatology online journal 1999;5:4.

22. Lin SW, Kaye V, Goldfarb N, et al.: Melanoma tumor seeding after punch biopsy. Dermatologic surgery : official publication for American Society for Dermatologic Surgery [et al] 2012;38:1083-1085.

23. Pflugfelder A, Weide B, Eigentler TK, et al.: Incisional biopsy and melanoma prognosis: Facts and controversies. Clinics in dermatology 2010;28:316-318.

24. Morton DL, Thompson JF, Cochran AJ, et al.: Final trial report of sentinel-node biopsy versus nodal observation in melanoma. The New England journal of medicine 2014;370:599-609.

25. Cormier JN, Xing Y, Ding M, et al.: Population-based assessment of surgical treatment trends for patients with melanoma in the era of sentinel lymph node biopsy. Journal of clinical oncology : official journal of the American Society of Clinical Oncology 2005;23:6054-6062.

26. Aitken JF, Youl P, Green A, et al.: Accuracy of case-reported family history of melanoma in Queensland, Australia. Melanoma research 1996;6:313-317.

27. Silva E: Adjunct primer for the use of national comprehensive cancer network guidelines for the surgical management of cutaneous malignant melanoma patients. World journal of surgical oncology 2012;10:54. 
TABLE I. Personal characteristics, diagnostic procedure and treatment of 787 patients with primary stage $1 \mathrm{~b}, 2$ melanoma

\begin{tabular}{|c|c|c|}
\hline Variable & $\mathrm{N}^{*}$ & $\%$ \\
\hline \multicolumn{3}{|l|}{ Age at diagnosis } \\
\hline$<50$ & 149 & 19 \\
\hline $50-69$ & 388 & 49 \\
\hline $70+$ & 250 & 32 \\
\hline Age at diagnosis (mean $\pm \mathrm{sd}$ ) & \multicolumn{2}{|c|}{$62( \pm 14)$} \\
\hline \multicolumn{3}{|l|}{ Sex } \\
\hline Female & 340 & 43 \\
\hline Male & 447 & 57 \\
\hline \multicolumn{3}{|l|}{ Location of residence } \\
\hline Major city & 450 & 57 \\
\hline Inner regional & 224 & 28 \\
\hline Outer regional/remote & 113 & 14 \\
\hline \multicolumn{3}{|l|}{ Site of melanoma } \\
\hline Head or neck & 167 & 21 \\
\hline Trunk & 273 & 35 \\
\hline Upper limb & 165 & 21 \\
\hline Lower limb & 182 & 23 \\
\hline \multicolumn{3}{|l|}{ Education } \\
\hline Junior school or less & 324 & 41 \\
\hline Completed senior school/trade/diploma & 307 & 39 \\
\hline Completed university/college degree & 155 & 20 \\
\hline \multicolumn{3}{|l|}{ Relationship status } \\
\hline No partner & 199 & 25 \\
\hline Partner & 586 & 75 \\
\hline \multicolumn{3}{|l|}{ Previous melanoma diagnosis } \\
\hline No & 587 & 77 \\
\hline Yes & 177 & 23 \\
\hline \multicolumn{3}{|l|}{ First degree blood relatives with melanoma } \\
\hline No & 547 & 70 \\
\hline Yes & 230 & 30 \\
\hline \multicolumn{3}{|l|}{ Diagnostic procedure } \\
\hline Excision & 580 & 74 \\
\hline Incision & 4 & 1 \\
\hline Shave & 111 & 14 \\
\hline Punch & 92 & 12 \\
\hline \multicolumn{3}{|l|}{ Health service sector } \\
\hline Public & 351 & 45 \\
\hline Private & 436 & 55 \\
\hline \multicolumn{3}{|l|}{ Initial treating doctor } \\
\hline GP & 478 & 61 \\
\hline GP at Skin cancer clinic & 155 & 20 \\
\hline General surgeon & 27 & 3 \\
\hline Plastic surgeon & 41 & 5 \\
\hline Dermatologist & 79 & 10 \\
\hline Other specialist & 7 & 1 \\
\hline
\end{tabular}


Follow-up surgery performed

Time (in days) from diagnosis to

follow-up surgery (mean $\pm \mathrm{sd}$ )

Type of follow-up surgery performed

WLE only

WLE + SLNB

Underwent additional WLE

Definitive treating doctor

GP

GP at Skin cancer clinic

General surgeon

Plastic surgeon

Dermatologist

Other specialist
766

97

$27( \pm 21)$

$505 \quad 66$

$261 \quad 34$

324

$58 \quad 8$

$36 \quad 5$

$410 \quad 54$

$246 \quad 32$

$14 \quad 2$

$2 \quad 0.3$

${ }^{*}$ For some characteristics, the summed total is less than the number of patients because of missing values. 
TABLE II. Location of residence, health service sector, treating doctor, site and thickness of primary melanoma by diagnostic procedure, $n=787$

\begin{tabular}{|c|c|c|c|c|c|}
\hline & \multirow[b]{2}{*}{ Total } & \multicolumn{4}{|c|}{ Diagnostic Procedure } \\
\hline & & Excision & Shave & Punch/Incision & $p$-value \\
\hline \multicolumn{6}{|l|}{ Location of residence } \\
\hline Major city & 450 & $322(72)$ & $79(18)$ & $49(11)$ & \\
\hline Inner regional & 224 & $165(74)$ & $24(11)$ & $35(16)$ & \\
\hline Outer regional/remote & 113 & $93(82)$ & $8(7)$ & $12(11)$ & 0.007 \\
\hline \multicolumn{6}{|l|}{ Health service sector } \\
\hline Public & 351 & $277(79)$ & $33(9)$ & $41(12)$ & \\
\hline Private & 436 & $303(70)$ & $78(18)$ & $55(13)$ & 0.002 \\
\hline \multicolumn{6}{|l|}{ Initial treating doctor } \\
\hline GP & 478 & $355(74)$ & $51(11)$ & $72(15)$ & \\
\hline GP at Skin cancer clinic & 155 & $120(77)$ & $24(15)$ & $11(7)$ & \\
\hline Surgeon & 68 & $58(85)$ & $4(6)$ & $6(9)$ & \\
\hline Dermatologist & 79 & $42(53)$ & $31(39)$ & $6(8)$ & \\
\hline Other specialist/Unknown & 7 & $5(71)$ & $1(14)$ & $1(14)$ & $<0.0001$ \\
\hline \multicolumn{6}{|l|}{ Site of Melanoma } \\
\hline Head and neck & 167 & $114(68)$ & $21(13)$ & $32(19)$ & \\
\hline Trunk & 273 & $206(75)$ & $46(17)$ & $21(8)$ & \\
\hline Upper limb & 165 & $132(80)$ & $17(10)$ & $16(10)$ & \\
\hline Lower limb & 182 & $128(70)$ & $27(15)$ & $27(15)$ & 0.005 \\
\hline Thickness, mm (mean $\pm s d)^{*}$ & 785 & $2.2(1.8)$ & $1.1(0.6)$ & $1.9(1.3)$ & $<0.0001$ \\
\hline $\begin{array}{l}\text { Time (in days) from initial } \\
\text { to follow-up surgery }{ }^{\dagger} \\
\text { (mean } \pm \text { sd) }\end{array}$ & 766 & $29(22)$ & $17(12)$ & $25(16)$ & $<0.0001$ \\
\hline
\end{tabular}


TABLE III. Personal characteristics, treating doctor, diagnostic procedure and histological characteristics of primary melanoma by sentinel lymph node biopsy

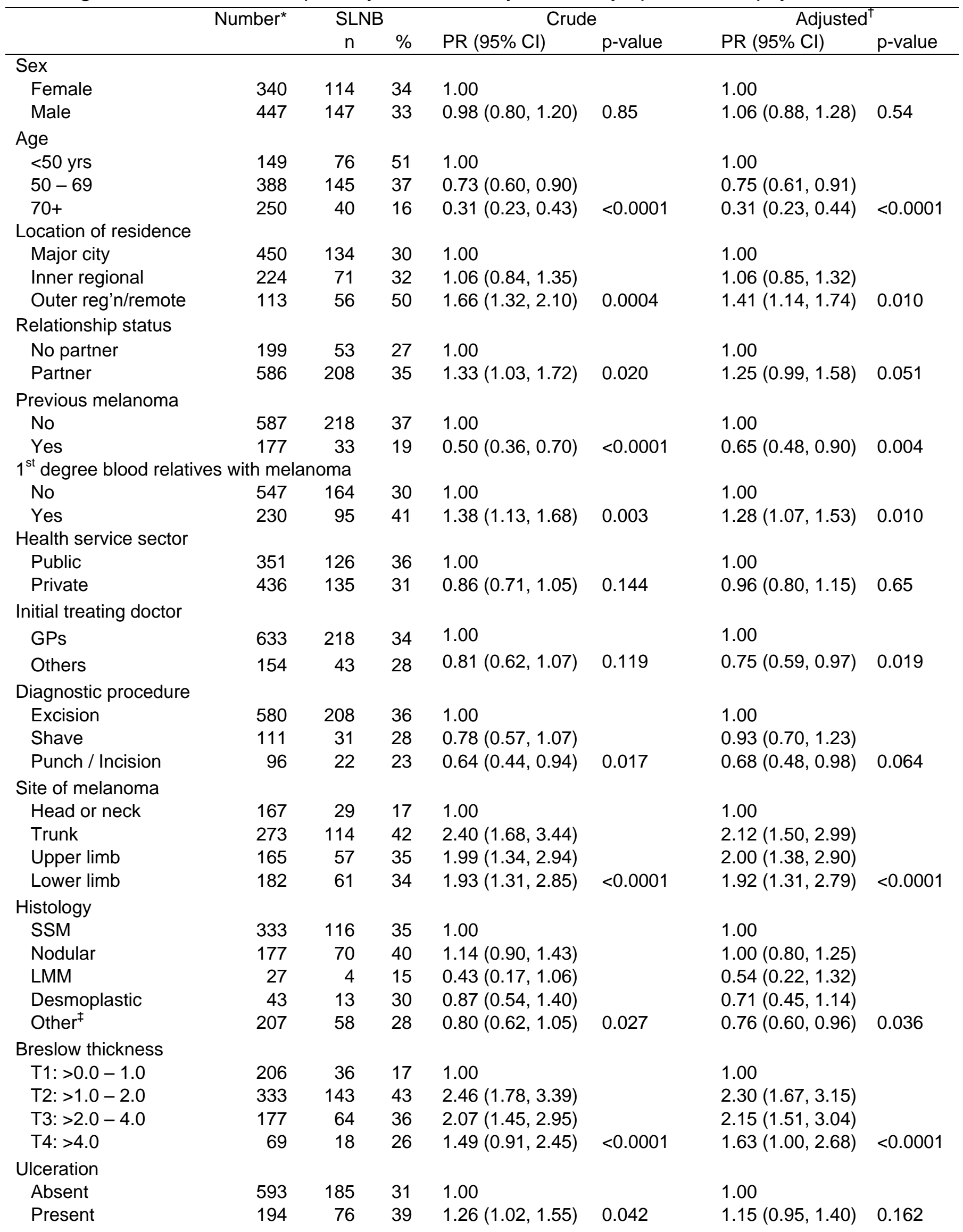




\section{T classification}

$2 a$

$206 \quad 36$

17

1.00

1.00

$2 b$

$258 \quad 109$

$42 \quad 2.42(1.74,3.36)$

$2.34(1.70,3.23)$

$3 a$

75

34

$45 \quad 2.59(1.76,3.82)$

$2.41(1.66,3.51)$

$3 b$

$119 \quad 40$

$34 \quad 1.92(1.30,2.84)$

$2.02(1.38,2.95)$

$58 \quad 24$

41

$2.37(1.55,3.63)$

$2.61(1.75,3.90)$

$4 a$

$\begin{array}{llll}29 & 5 & 17 & 0.99(0.42,2.31)\end{array}$

$1.21(0.52,2.80)$

$4 \mathrm{~b}$

$40 \quad 13$

33

$1.86(1.09,3.18) \quad<0.0001$

$2.08(1.25,3.48)$

${ }^{*}$ For some factors, the summed total is less than 787 because of missing values.

${ }^{\dagger}$ Adjusted for age, sex, thickness and ulceration; $T$ stage adjusted for age and sex only;

${ }^{\ddagger}$ Includes $n=142$ unable to classify/not stated, $n=31$ naevoid, $n=12$ mixed, $n=22$ other

$\mathrm{PR}$ - prevalence ratio

$95 \% \mathrm{Cl}-95 \%$ confidence interval 